\section{PRACTICAL CHILD PSYCHOTHERAPY}

By Curt Baenheim, M.D. 2nd Edition. Pp. 184 . London: Staples Press, Ltd. I953. I5s.

This book has been written for the general practitioner. A section on psychotherapy, its indications and methods, precedes the main body of the book, which is devoted to a very useful account of psychosomatic illness in childhood. There are chapters on alimentary, urinary, sexual, motor and habit disorders. Cardiac neurosis, vasomotor disorders, migraine and asthma are also discussed.

The material is good though the author's style is at times rather difficult. By and large a helpful book.

\section{J.D.W.P.}

\section{EMOTIONAL FACTORS IN SKIN DISEASE}

By E. WittKower, M.D., and B. Russell, M.D., - F.R.C.P., D.P.H. Pp.x + 214. London: Cassell \& Co., Ltd. 1953. 32s. 6d.

Here is a subject of great importance to the dermatologist and well worthy of a monograph. The advances of medicine of the past decades have changed the spectrum of skin diseases. The majority of cases now seen are those which find consideration by the authors, pruritus of various types, psoriasis, rosacea, urticaria, eczema, seborrhoeic dermatitis, acne and alopecia.

In the opening chapters Dr. Russell rightly devotes space to the anatomy and physiology of the skin and traces the ways in which the emotions might produce somatic skin changes. Unfortunately he already prejudges the issue by declaring that many skin disorders are psychogenic before the evidence has been marshalled. Nevertheless he gives a valuable reminder of the importance of taking a medical history even when the disorder can be recognized at a glance. On the other hand the desirability of taking a psychomatic history as a routine is open to question.

The remainder of the book is contributed by psychiatrists. It comprises a series of personality studies of skin patients, including soldiers, who had in common a certain dermatological disorder. An attempt is made to find a predominant pattern of psychopathology and to fit it to a corresponding dermatosis.
Much space is taken up in detailing case histories of patients and listing their unfavourable character traits. Granted, however, that many skin patients are worriers, are nervy or even obviously psychopathic, that by itself is not certain proof that the emotional factor is the main one in producing the skin disease.

M.F.

GYNAECOLOGICAL AND OBSTETRICAL ANATOMY AND FUNCTIONAL HISTOLOGY By C. F. V. Smout, M.D., M.R.C.S., and F. JACOBY, M.D., Ph.D. 3rd Edition. Pp. vii + 336, with 185 illustrations. London: Edward Arnold \& Co. 1953. 35s.

A truth that is not always appreciated is that the one essential basis for the practice of a speciality is a working knowledge of the functional anatomy of the regions with which the speciality is concerned. This knowledge cannot be acquired in sufficient detail from textbooks of general anatomy so a special book is needed, and Smout and Jacoby's book has fulfilled the requirements of gynaecologists, making understandable the, complexities of the anatomy of the female pelvis.

The new edition improves on its predecessors by virtue of its full quotation from recognized papers published in the past five years. The bibliography at the end of each chapter is a model of how a bibliography should be prepared. A short historical summary is given which is interesting and accurate, but not essential to the understanding of obstetrical anatomy. The additional material of a histologicalô nature does, however, add greatly to appreciation of $\supsetneq$ function, and does enable the practising gynaecologist to speak on equal terms with the histologist, whose task it is to report on the majority of curettings.

In the main the excellent illustrations are adequate but an attempt to follow the course of the ureter in the pelvis was made much easier with the aid of the colour illustration in the second edition than with the poorly reproduced Fig. $5 \mathrm{I}$ in the third edition.

It is difficult to see how a candidate can today present himself for the M.R.C.O.G. examination without studying Smout and Jacoby first. He could in no other way learn so easily and accurately the very basis on which his knowledge must be founded.

E.E.P.
NOTICE OF SPECIAL INTEREST TO SUBSCRIBERS: "WHY NOT HAVE YOUR COPIES OF THIS
JOURNAL BOUND INTO YEARLY VOLUMES?"

Arrangements have now been made to have the twelve monthly issues fully bound in dark green pin head eloth, lettered in gilt on spine with name of Journal, Volume Number and year, complete with index at front, 17s. 6d. per Volume, post free. A limited number of out of print journals are available to bind into volumes and make your library complete. Price on application giving details of issues required to complete back volumes.

THE FELlOWSHIP OF POSTGRADUATE MEDICINE 60 PORTLAND PLACE, LONDON, W.I

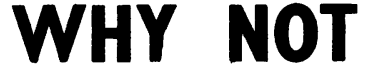

HAVE YOUR JOURNALS BOUND? 